\title{
Electrocatalytic Oxygen Reduction in Alkaline Medium at Graphene-Supported Silver-Iron Carbon Nitride Sites Generated During Thermal Decomposition of Silver Hexacyanoferrate
}

\author{
Beata Dembinska ${ }^{1}$ D $\cdot$ Kamila Brzozowska $^{1} \cdot$ Adam Szwed $^{1} \cdot$ Krzysztof Miecznikowski $^{1} \cdot$ Enrico Negro $^{2}$. \\ Vito Di Noto ${ }^{2}$. Pawel J. Kulesza ${ }^{1}$
}

Published online: 29 November 2018

(C) The Author(s) 2018

\begin{abstract}
Silver-iron carbon nitride, which has been prepared by pyrolysis (under inert atmosphere) of silver hexacyanoferrate(II) deposited on graphene nanoplatelets, is considered here as electrocatalyst for oxygen reduction in alkaline medium $(0.1 \mathrm{M}$ potassium hydroxide electrolyte) in comparison to simple silver nanoparticles and iron carbon nitride (prepared separately in a similar manner on graphene nanoplatelets). The performance of catalytic materials has been examined using such electrochemical diagnostic techniques as cyclic voltammetry and rotating ring-disk electrode voltammetry. Upon application of the graphene nanoplatelet-supported mixed silver-iron carbon nitride catalyst, the reduction of oxygen proceeds at more positive potentials, as well as the amounts of hydrogen peroxide (generated during reduction of oxygen at potentials more positive than $0.3 \mathrm{~V}$ ) are lower relative to those determined at pristine silver nanoparticles and iron carbon nitride (supported on graphene nanoplatelets), when they have been examined separately. The enhancement effect shall be attributed to high activity of silver toward the reduction/ decomposition of $\mathrm{H}_{2} \mathrm{O}_{2}$ in basic medium. Additionally, it has been observed that the systems based on carbon nitrides show considerable stability due to strong fixation of metal complexes to $\mathrm{CN}$ shells.
\end{abstract}

Keywords Graphenenanoplatelets · Carbon nitride electrocatalyst · Silver · Iron · Oxygen reduction reaction · Hydrogen peroxide intermediate $\cdot$ Alkaline fuel cell

\section{Introduction}

Proton-Exchange Membrane Fuel Cells (PEMFCs) are promising environmentally friendly electrochemical devices for energy conversion and are still dominating research on lowtemperature fuel cells, but, in recent years, substantial progress in fabrication and utilization of anion exchange membranes

Beata Dembinska

bbaranowska@chem.uw.edu.pl

$\triangle$ Pawel J. Kulesza

pkulesza@chem.uw.edu.pl

1 Faculty of Chemistry, University of Warsaw, Pasteura 1, PL-02-093 Warsaw, Poland

2 Department of Industrial Engineering, University of Padova, Via Marzolo 9, I-35131 Padova (PD), Italy has driven growing interest in Alkaline Fuel Cells (AFCs) [1, 2]. Relative to acidic electrolytes, such general features as faster dynamics of the oxygen reduction reaction and larger availability of catalytic systems in alkaline media [3, 4] justify substitution of platinum and platinum group metals with more abundant and less expensive materials like silver [4-9], transition metals (especially $\mathrm{Fe}, \mathrm{Co}$ ), particularly when coordinated with nitrogen [10-13], transition metal oxides [14, 15], or even carbon nanostructures doped with heteroatoms $(\mathrm{N}, \mathrm{S}, \mathrm{P}$, B) [16-19].

Among the most widely studied oxygen reduction catalysts in alkaline media are the carbon-supported nitrogen-coordinated iron systems (abbreviated as FeNC) obtained via hightemperature pyrolysis of simple precursors. Structurally, the active sites are believed to resemble the centers existing in such macromolecular complexes as porphyrins or phthalocyanines. An interesting recent approach describes the carbon nitride-based electrocatalysts prepared through thermal decomposition of hexacyanometalates in which the carbon- 
based matrix embeds nitrogen atoms capable of coordination of metallic species [20-28]. Among advantages coming from the use of hexacyanometalates as starting compounds is the possibility of fabrication of materials of controlled stoichiometry with mixed metallic species (e.g., Fe, Co, Ni, Sn, Mn, Cu, $\mathrm{Ag})$.

Due to appreciable electrocatalytic activity and reasonable stability during both oxygen and hydrogen peroxide reduction reactions [4-9, 29, 30], silver can be considered as promising alternative to platinum for studies in alkaline media. The mechanism of oxygen reduction on $\mathrm{Ag}$ usually is reported to proceed predominantly to water. When it comes to structural dependence of the oxygen reduction kinetics, it tends to increase according to the following order of planes: (100) $<(111)<(110)$ [31]. It is also noteworthy that fairly active and stable materials have been obtained by combining silver with manganese oxides [32, 33], cobalt oxides [34], molybdenum oxides [35], and other transition metals $(\mathrm{Co}, \mathrm{Cu}, \mathrm{Ni}$, $\mathrm{Sn}, \mathrm{Fe})[36-40]$.

Among important issues concerning preparation of the cathode materials for operation in low-temperature alkaline fuel cells is the need of utilization of carbon supports of high electrochemically accessible surface area and suitable porosity for proper mass transport. Special attention has been paid to high graphitization degree which determines electron conductivity and stability of the whole electrocatalytic system. Relative to the systems based on conventional carbon blacks [41, 42], various graphene-related materials with their unique properties have also been considered with an ultimate goal of increasing effectiveness and stability of catalysts [43, 44]. Nevertheless, the absence of surface functional groups and defects complicates utilization of pristine graphene as matrix for immobilization of the homogenously distributed largely dispersed active centers. Consequently, more porous and defected graphene oxide (GO) and reduced graphene oxide (rGO) have been more broadly studied as supports (or their precursors) capable of anchoring finely dispersed catalytic nanoparticles. However, stability of such materials and their electronic conductivity has often been reported as insufficient $[42,45]$. On the other hand, it has recently been demonstrated that durability can be improved through application of the polyelectrolyte-modified graphene nanoplatelets (GNP) as supports for Pt nanoparticles. In this respect, the intrinsic high graphitization degree of GNP and the enhanced interactions between Pt and carbon (GNP) have been described as advantageous in Pt/GNP [46]. Finally, irrespective of the choice of graphene-type material, the problem of gas permeability and water management (originating from so-called stacking effect) leads to lower intrinsic performance of cathodes during oxygen reduction reaction in relation to those based on other carbon nanostructures. In fact, graphene and its derivatives can be used as fairly effective additives to gas-barrier systems [47]. The latter problem can be addressed by designing three-dimensional morphologies of composite assemblies in which additives of other carbonaceous materials act as spacers between the graphene-type sheets [42, 45, 48-50]. Durability of such hybrid systems seems to be significantly improved.

Nitrogenated derivatives of graphene-related materials have recently been also considered as supports or modifiers for silver-based electrocatalysts active toward oxygen reduction in alkaline environment [51-54]. In the present work, we address fabrication and physicochemical identity of the graphene-nanoplatelet-supported silver-iron carbon nitride catalytic systems derived from thermal decomposition of silver(I) hexacyanoferrate(II) deposited onto polycarboxylate-functionalized GNP. The resulting material is elucidated for oxygen reduction reaction (ORR) in $0.1 \mathrm{M}$ $\mathrm{KOH}$, and the system's activity is compared to the performance of pristine silver nanoparticles and iron carbon nitride (prepared separately in a similar manner on GNP and investigated under analogous conditions). Regarding strong fixation of metal centers coordinated within $\mathrm{CN}$ shells, the stability issue of examined systems is also discussed.

\section{Experimental}

All chemicals were commercial materials of the highest available purity. $\mathrm{HClO}_{4}$, ethanol, 2-propanol, $\mathrm{KOH}$, and $\mathrm{K}_{4}\left[\mathrm{Fe}(\mathrm{CN})_{6}\right] \cdot 3 \mathrm{H}_{2} \mathrm{O}$ were from POCh (Poland). The solution of 5\% Nafion-1100, as well as $\mathrm{AgNO}_{3}, \mathrm{Fe}_{2}\left(\mathrm{SO}_{4}\right)_{3} \cdot 6 \mathrm{H}_{2} \mathrm{O}$, and the polycarboxylate-functionalized graphene nanoplatelets (GNP) were from Sigma-Aldrich. Vulcan XC-72R (C) was from Cabot (USA); graphene oxide sheets (GO) of 300 $700 \mathrm{~nm}$ sizes (thickness, $1.1 \pm 0.2 \mathrm{~nm}$ ) were from Megantech; $\operatorname{Pt}(20 \%) / \mathrm{C}$ was from E-Tek; $30 \%$ hydrogen peroxide was from Chempur (Poland); and the nitrogen, oxygen, and argon gases (purity 99.999\%) were from Air Products (Poland). As a rule, the solutions were prepared from doubly distilled and subsequently deionized (Millipore Milli-Q) water.

Preparation of graphene nanoplatelets (GNPs) modified with silver hexacyanoferrate $\left(\operatorname{Ag}_{4}^{\mathrm{I}}\left[\mathrm{Fe}^{\mathrm{II}}(\mathrm{CN})_{6}\right]\right)$, abbreviated as $A g_{4} H C F / G N P$, was achieved by precipitation method. In the actual procedure, the mixture of $15.1 \mathrm{~cm}^{3}$ of water, $2 \mathrm{~cm}^{3}$ of ethanol, and $50 \mathrm{mg}$ of GNP was first placed for $1 \mathrm{~h}$ in an ultrasonic bath to obtain good dispersion. Then, $10.3 \mathrm{~cm}^{3}$ of $10 \mathrm{mmol} \mathrm{dm}{ }^{-3} \mathrm{AgNO}_{3}$ aqueous solution was added, and the slurry was left in the bath for about $15 \mathrm{~min}$ followed by mixing under magnetic stirring. After 10 min of mixing, $2.6 \mathrm{~cm}^{3}$ of $10 \mathrm{mmol} \mathrm{dm}^{-3} \mathrm{~K}_{4}\left[\mathrm{Fe}(\mathrm{CN})_{6}\right]$ water solution was added, and the dispersion was left for ca. $5 \mathrm{~h}$ to assure full precipitation of the product (white sediment in a blank test). Total volume of mixture was $30 \mathrm{~cm}^{3}$. In the next step, the solution was centrifuged and removed. The sediment was washed three times with water and dried on a hot plate at about $60{ }^{\circ} \mathrm{C}$. When 
taking into account the amounts of GNP and precursors used for synthesis, and assuming that the main precipitate is $\mathrm{Ag}_{4}^{\mathrm{I}}\left[\mathrm{Fe}^{\mathrm{II}}(\mathrm{CN})_{6}\right]$, the overall content of $\mathrm{Ag}$ and $\mathrm{Fe}$ in the sample was on the level of $20 \%$ relative to GNP.

Preparation of GNPs modified with Prussian Blue $\left(\mathrm{Fe}^{\mathrm{III}}{ }_{4}\left[\mathrm{Fe}^{\mathrm{II}}(\mathrm{CN})_{6}\right]\right), \mathrm{Fe}_{4} H C F_{3} / G N P$, was pursued in an analogous manner as for $\mathrm{Ag}_{4} \mathrm{HCF} / G N P$, except that, in order to obtain the "insoluble" (largely $\mathrm{K}^{+}$-free) form of Prussian Blue postulated previously, $\mathrm{Fe}^{3+}$ was used in excessive (super stoichiometric amounts). Consequently, during the synthesis, $7.4 \mathrm{~cm}^{3}$ of $10 \mathrm{mmol} \mathrm{dm}{ }^{-3}$ solution of $\mathrm{Fe}_{2}\left(\mathrm{SO}_{4}\right)_{3}$ and $9.6 \mathrm{~cm}^{3}$ of $10 \mathrm{mmol} \mathrm{dm}^{-3} \mathrm{~K}_{4}\left[\mathrm{Fe}(\mathrm{CN})_{6}\right]$ were added. The amount of water and ethanol solutions was adjusted to the level of $30 \mathrm{~cm}^{3}$ of the total volume. The resulting material (dark blue sediment in a blank test) was washed and dried. The content of Fe in the sample was on the level of $20 \%$ by weight relative to GNP.

Preparation of GNPs modified with silver nitrate $\left(\mathrm{Ag}^{\mathrm{I}} \mathrm{NO}_{3}\right), \mathrm{AgNO}_{3} / G N P$, was accomplished by a simple impregnation method; namely, to $18.4 \mathrm{~cm}^{3}$ of the homogenized dispersion of GNP in water-ethanolic solution, $11.6 \mathrm{~cm}^{3}$ of $10 \mathrm{mmol} \mathrm{dm}^{3} \mathrm{AgNO}_{3}$ was added. The slurry was subjected to magnetic stirring for several hours; later, the solvent was evaporated under ambient conditions $\left(22^{\circ} \mathrm{C}\right)$. The content of $\mathrm{Ag}$ in the sample was ca. $20 \%$ by weight relative to GNP.

All prepared samples were subjected to grinding in agate mortar and, subsequently, annealed in a silica tube under $\mathrm{Ar}$ atmosphere at $800{ }^{\circ} \mathrm{C}$ for $2 \mathrm{~h}$ (with the heating up rate of an oven, $\left.4{ }^{\circ} \mathrm{C} \mathrm{min}^{-1}\right)$. The heat-treated samples are labeled $\mathrm{AgFeCN} N_{x} / G N P 800, \mathrm{FeCN}_{x} / G N P 800$, and $\mathrm{Ag} / G N P 800$. For comparison, pristine GNP was also washed with water and annealed under the same conditions as described previously (it is labeled GNP800). The additional sample of $A g F e C N_{x}$ GO800 was prepared.

The electrochemical measurements were performed with CH Instruments (Austin, TX, USA) Model 750D and 920D workstations. All electrochemical experiments were conducted at room temperature, $22 \pm 2{ }^{\circ} \mathrm{C}$. The mercury-mercury sulfate electrode $\left(\mathrm{Hg} / \mathrm{Hg}_{2} \mathrm{SO}_{4}\right)$ (in acid medium) and the saturated calomel electrode (SCE) (in alkaline medium) were used as reference electrodes. In the latter case, care was exercised to use a high-quality bridge to avoid contamination of the electrolyte with chlorides. As a rule, all potentials were recalculated by usual means and expressed against the standard RHE. Glassy carbon rod served as counter electrodes. The rotating ring-disk electrode (RRDE) experiments were performed using a variable speed rotator (Pine Instruments, USA). The electrode assembly utilized a glassy carbon disk (with geometric area of $0.247 \mathrm{~cm}^{2}$ ) and Pt ring. The collection efficiency $(\mathrm{N})$ of the RRDE assembly was equal to 0.388 , as determined from the ratio of ring and disk currents (at $1600 \mathrm{rpm})$ using the argon-saturated $0.005 \mathrm{~mol} \mathrm{dm}^{-3}$ $\mathrm{K}_{3}\left[\mathrm{Fe}(\mathrm{CN})_{6}\right]$ in $0.1 \mathrm{~mol} \mathrm{dm}{ }^{-3} \mathrm{~K}_{2} \mathrm{SO}_{4}$ solution. Before electrode layer preparation, working electrodes were polished with aqueous alumina slurries (grain size, 5-0.05 $\mu \mathrm{m}$ ) on a Buehler polishing cloth. In the course of RRDE experiments, in order to oxidize $\mathrm{H}_{2} \mathrm{O}_{2}$ (generated at the disk) under convection-diffusional control, the potential of the ring electrode was kept at $1.23 \mathrm{~V}$ vs. RHE.

Electrode layers were deposited on a glassy carbon disk by dropping appropriate volumes of homogenized inks containing $5 \mathrm{mg}$ of nanostructured catalyst admixed with Vulcan ${ }^{\circledR}$ $\mathrm{XC}-72 \mathrm{R}$ (labeled as $\mathrm{C}$ ) in the mass ratio of 1 to $1,500 \mu \mathrm{l}$ of solvent (2-propanol) and $6 \mu$ l of binder (5\% solution of Nafion () . They were subsequently dried at room temperature, $22 \pm 2{ }^{\circ} \mathrm{C}$. The final content of Nafion $\AA$ was $5 \%$ in relation to the weight of catalyst and Vulcan. Catalyst loadings were $600 \mu \mathrm{g} \mathrm{cm}^{-2}$. In comparative measurements with the $\mathrm{Pt}(20 \%) / \mathrm{C}$ standard, the Pt loading was $15 \mu \mathrm{g} \mathrm{cm}^{-2}$. The electrodes covered with the catalytic layers were typically washed out with the stream of water (in order to clean the surface from impurities) and, later, subjected to voltammetric potential cycling at the scan rate of $100 \mathrm{mV} \mathrm{s}^{-1}$ in the nitrogen-saturated $0.1 \mathrm{~mol} \mathrm{dm}^{-3} \mathrm{KOH}$ in the potential range from 0.05 to $1.05 \mathrm{~V}$ to activate the layers and receive reproducible responses. To assure reproducibility of the electrode preparation and its performance, we have conducted electrochemical experiments at least three times. The data were reproducible within ca. $5 \%$.

In the experiments involving the preconditioning step (labeled $P$ ), the electrode was cycled in nitrogen-saturated $0.1 \mathrm{M}$ $\mathrm{HClO}_{4}$ solution in the range of $0.05-1.05 \mathrm{~V}$ at the scan rate of $100 \mathrm{mV} \mathrm{s}^{-1}$ until stable (flat) response was obtained. The electrolyte was changed twice during the experiments.

In the additional experiments conducted in $0.5 \mathrm{M} \mathrm{K}_{2} \mathrm{SO}_{4}$, which were aiming at obtaining the electrochemical characteristics of precursors, $\mathrm{Fe}_{4} \mathrm{HCF}_{3} / G N P, \mathrm{Ag}_{4} \mathrm{HCF} / G N P$, and the GNP carrier, the respective inks were prepared without Vulcan additive and loadings of the respective electrode layers were on the level of $300 \mu \mathrm{g} \mathrm{cm}{ }^{-2}$.

Transmission Electron Microscopy (TEM) experiments were carried out with Libra 120 EFTEM (Carl Zeiss) operating at $120 \mathrm{kV}$. Scanning electron microscopic (SEM) measurements and energy-dispersive X-ray analysis were achieved using MERLIN FE-SEM (Carl Zeiss) equipped with EDX analyzer (Bruker). X-Ray diffraction (XRD) spectra were collected using Bruker D8 Discover equipped with a $\mathrm{Cu}$ lamp (1.54 $\AA$ ) and Vantec (linear) detector.

\section{Results and Discussion}

\section{General Physicochemical Characteristics}

Figure 1 illustrates representative SEM and TEM images of bare GNP800 support and after its modification with catalytic nanostructures (typically nanoparticles). It is evident from 

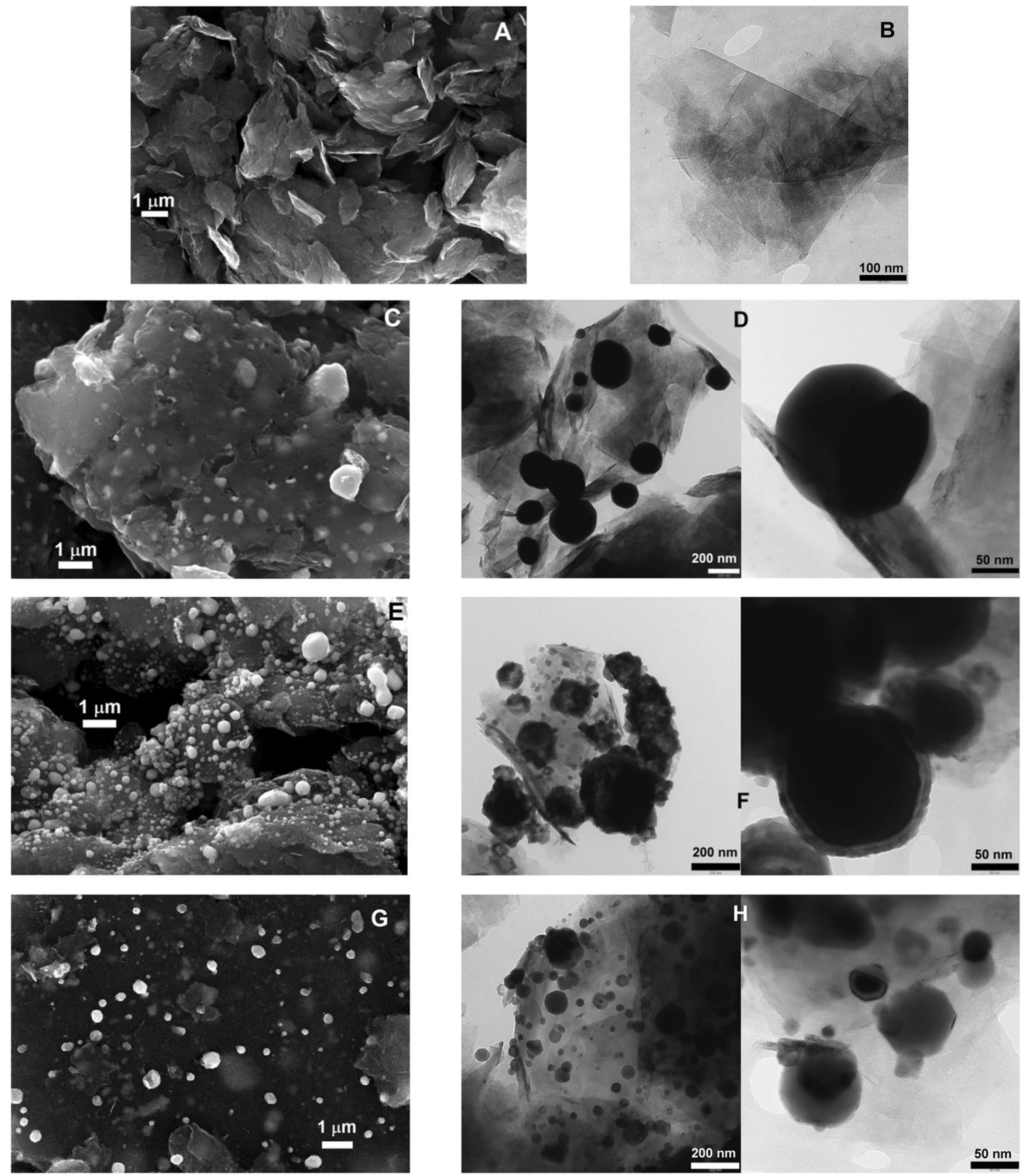

Fig. $1 \mathrm{SEM}(\mathrm{WD}=6 \mathrm{~mm}, \mathrm{EHT}=15 \mathrm{kV})$ and TEM images of the following materials: (a,b) $G N P-800,(\mathbf{c}, \mathbf{d}) \mathrm{Ag} / G N P 800,(\mathbf{e}, \mathbf{f}) \mathrm{FeCN} / G N P 800$, and (g,h) $\mathrm{AgFeCN} / \mathrm{GNP800}$

Fig. 1a,b that the GNP support indeed exists in the form of platelets with the sizes ranging from few hundred nanometers up to few micrometers. In the case of $A g / G N P 800$ (Fig. 1c,d), silver deposit forms fairly large nano-, or submicro-, particles with diameters ranging from 50 to $200-300 \mathrm{~nm}$, and virtually, no smaller species could be observed in the series of images. TEM images of precursor $\left(\mathrm{AgNO}_{3}\right)$ recrystallized onto GNP (for simplicity, data are not shown here) clearly show that presence of the polycarboxylate-modified GNPs enables good dispersion of crystallites having diameters from few to tens of nanometers (but usually not exceeding $100 \mathrm{~nm}$ ). It is reasonable to expect that the aggregation occurs under high temperature $\left(800{ }^{\circ} \mathrm{C}\right)$ of annealing. In contrast, the micrographs of $\mathrm{FeCN}_{x} / G N P 800$ (Fig. 1e,f) and $\mathrm{AgFeCN} N_{x} / G N P 800$ (Fig. 1g,h) imply diversity of sizes: in addition to particles with diameters of hundreds of nanometers, there is also appreciable population of much smaller species. Therefore, it may be concluded that the application of the precursors in the form of such inorganic metal clusters as Prussian Blue and its analogs lowers (at least to a certain degree) sintering of metal nanoparticles. 
Another important observation concerns samples $\mathrm{FeCN} \mathrm{N}_{x}$ GNP800 (Fig. 2f) and $A g F e C N_{x} / G N P 800$ (Fig. 2h) where metal nanoparticles are embedded in a shell somewhat reflecting stoichiometry of the starting material. The results are in agreement with the previous reports [23-27] postulating the existence of metal nanoparticles within a compact carbon nitride shell $(\mathrm{CN})$.

The EDX analysis of the materials generally reflects ratios and amounts of precursors used for their synthesis. In the case of $\mathrm{Fe}_{4} \mathrm{HCF}_{3} / \mathrm{GNP}$ (before annealing), the molar ratio of $\mathrm{Fe}$ to $\mathrm{N}$ is 0.5 (which is close to the value 0.4 expected from the stoichiometry of the $\mathrm{Fe}^{\mathrm{III}}{ }_{4}\left[\mathrm{Fe}^{\mathrm{II}}(\mathrm{CN})_{6}\right]$ ) compound); however, after pyrolysis (sample $\mathrm{FeCN}_{x} / G N P 800$ ), the ratio of Fe to N has substantially changed to the value closer to 10 thus implying substantial loss of nitrogen species. The data obtained for $\mathrm{Ag}_{4} \mathrm{HCF} / \mathrm{GNP}$ (before annealing) are consistent with the molar ratio of the elements $\mathrm{Ag}: \mathrm{Fe}: \mathrm{N}$ which is $3: 1: 6$ and for $\mathrm{AgFeCN} / \mathrm{GNP} 800$ (after annealing), the composition changes into the order, 3:1:3, again implying the loss of $\mathrm{N}$. The analytical data also imply the presence of carbon, oxygen, as well as some content of potassium. The EDX mapping of $\mathrm{FeCN}_{x} /$ GNP800 (Fig. 2a) shows fairly homogenous distribution of N and $\mathrm{Fe}$. In the case of $\mathrm{AgFeCN} N_{x} / G N P 800$ (Fig. 2b), the distribution of signals originating form $\mathrm{Fe}$ and $\mathrm{Ag}$ is less homogeneous: they tend to superimpose in certain areas thus implying the mixed nature of obtained nanoparticles.

As shown in Fig. 3a, the XRD pattern of $A g / G N P 800$ illustrates peak characteristic of the face-centered cubic (fcc)

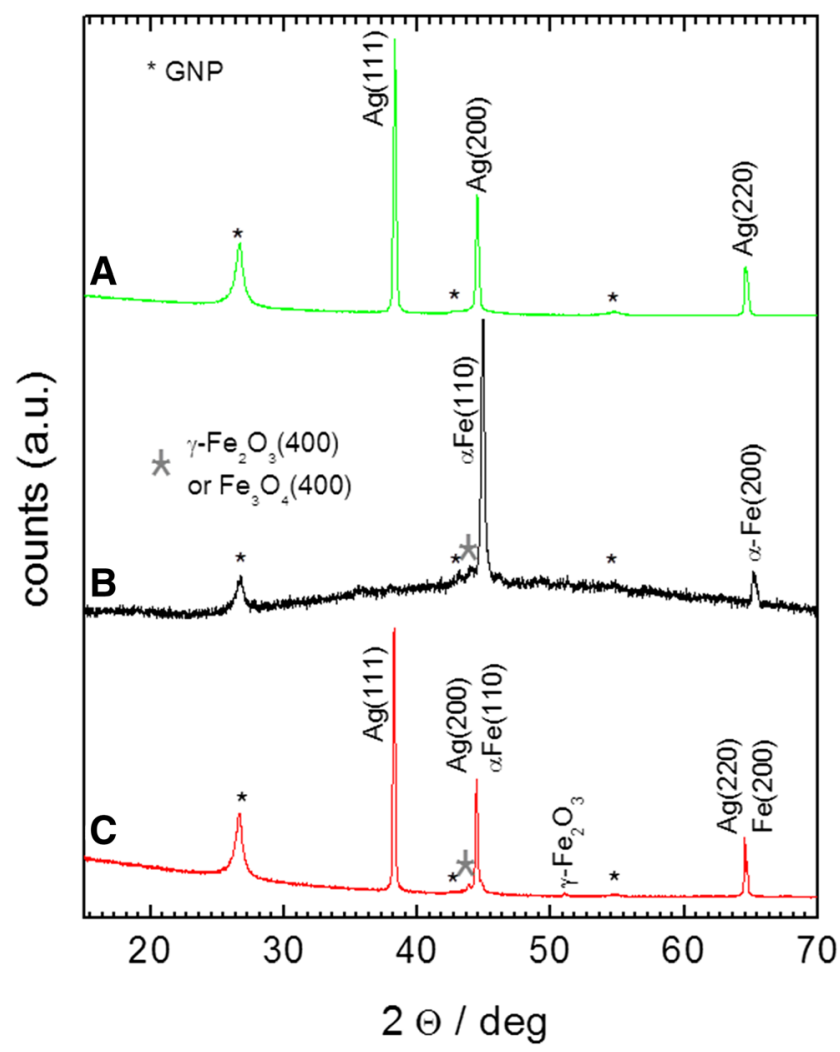

Fig. 3 XRD patterns of the following samples: (a) $A g / G N P 800$, (b) $\mathrm{FeCN}_{x} / G N P 800$, and (c) $\mathrm{AgFeCN} / G N P 800$

\section{A}
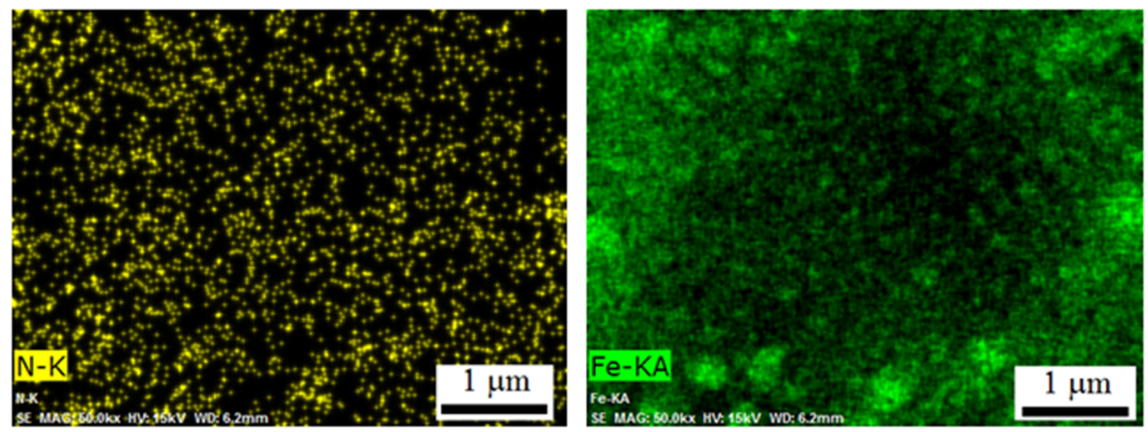

B
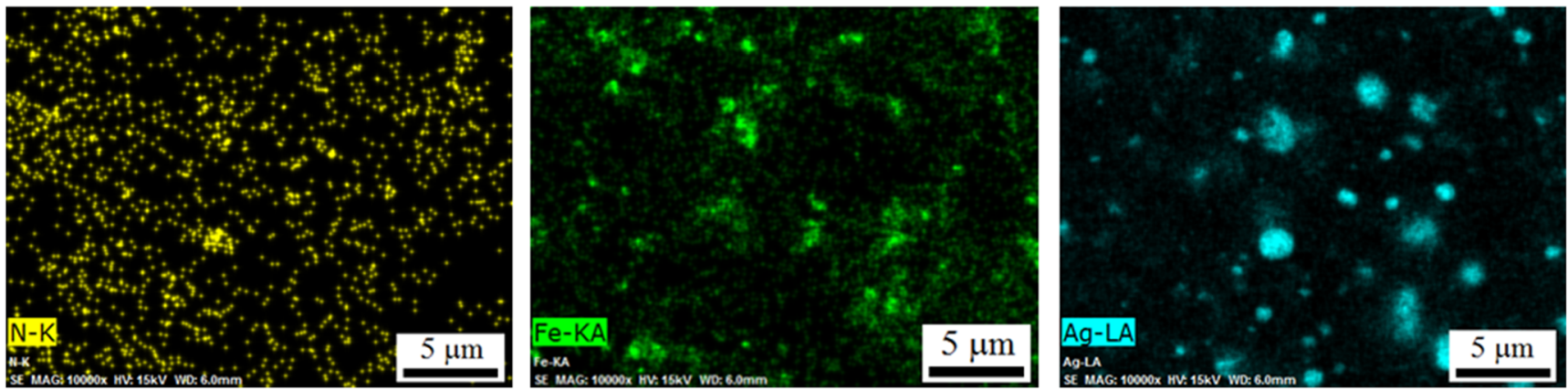

Fig. 2 Elemental EDX mapping of the following materials: (a) $\mathrm{FeCN}_{x} / G N P 800$ and (b) $\mathrm{AgFeCN} / \mathrm{GNP} 800$ 
crystal structure of $\mathrm{Ag}((111),(200)$, and (220)) with the cell parameter of $4.083 \AA$ and the average crystallite size of $51.7 \mathrm{~nm}$ (calculated using the Scherrer's equation). In the XRD spectrum of $\mathrm{FeCN}_{x} / G N P 800$ (Fig. 3b), the main reflections correspond to the body-centered cubic structure (bcc) of $\alpha$-Fe ((110) and (200)) with the cell parameter of $2.862 \AA$ and the average crystallite size of $32.7 \mathrm{~nm}$. Some other, but much less distinct, peaks (Fig. 3b) could be ascribed to the traces of oxide forms of iron, like $\gamma-\mathrm{Fe}_{2} \mathrm{O}_{3}$ or $\mathrm{Fe}_{3} \mathrm{O}_{4}$. One has to be aware that, for Fe-containing materials, the fluorescence of $\mathrm{X}$ rays, appearing when a $\mathrm{Cu}$ lamp is used, tend to increase the background noise. In the case of $\mathrm{AgFeCN} N_{x} / G N P 800$ (Fig. 3c), in addition to signal characteristic of $\mathrm{Ag}$ and $\alpha$-Fe, there are also small peaks most likely originating from the traces of iron oxides. Here, the cell parameter for $\mathrm{Ag}$ is $4.075 \AA$ (average crystallite size of $\mathrm{Ag}$ is $92.8 \mathrm{~nm}$ ) and for Fe is $2.886 \AA$ (average crystallite size of $\mathrm{Fe}$ is $104.6 \mathrm{~nm}$ ). It should be remembered that the Scherrer's formula constitutes an approximation, and it gives reliable results for nearly spherical particles. In all patterns, the GNP support reflections are present $((002)$, (111), and (004)), thus indicating partial stacking.

An evidence for the presence of the corresponding cyanometallate compounds (silver and iron(III) hexacyanoferrates(II)) on the surface of GNPs has been examined using cyclic voltammetry (conducted in $0.5 \mathrm{M} \mathrm{K}_{2} \mathrm{SO}_{4}$ ). Figure 4a shows voltammograms recorded for $\mathrm{GC}$ electrode covered with (a) $\mathrm{Fe}_{4} \mathrm{HCF}_{3} / G N P$ and (b) $\mathrm{Ag}{ }_{4} \mathrm{HCF} / G N P$, in comparison to (c) the GNP support itself. The voltammetric response recorded for $\mathrm{Fe}_{4} \mathrm{HCF}_{3} / G N P$ (blue line in Fig. 4a) resembles the well-known pattern characteristic of $\mathrm{PB}$ in which the partial oxidation to iron(III) hexacyanoferrate(III) or Prussian Yellow proceeds at about 1.2 V, and the reduction to iron(II) hexacyanoferrate(II) or Prussian White appears at about $0.4 \mathrm{~V}[55,56]$. In the case of $\mathrm{Ag}_{4} \mathrm{HCF} / \mathrm{GNP}$, the representative voltammogram (red line in Fig. $4 \mathrm{a}$ ) has been recorded after the first few scans, in which some $\mathrm{Ag}^{+}$has been replaced with potassium ions during oxidation of hexacyanoferrate(II) component to hexacyanoferrate(III) [55, 56]. The latter response resembles typical behavior of silver(I) hexacyanoferrate(III) in $\mathrm{K}^{+}$-containing electrolytes, where the reversible couple of peaks at about $0.95 \mathrm{~V}$ corresponds to $\mathrm{Ag}_{3} \mathrm{~K}\left[\mathrm{Fe}^{\mathrm{II}}(\mathrm{CN})_{6}\right] / \mathrm{Ag}_{3}\left[\mathrm{Fe}^{\mathrm{III}}(\mathrm{CN})_{6}\right]$ transitions $[57,58]$.

Figure $4 \mathrm{~b}$ presents cyclic voltammetric responses of (a) $\mathrm{Ag}$ / GNP800-C, (b) $\mathrm{FeCN}_{x} / G N P 800-\mathrm{C}$, (c) $\mathrm{AgFeCN} \mathrm{N}_{x} / G N P 800-\mathrm{C}$, and (d) GNP800-C layers deposited on glassy carbon electrode recorded in the de-aerated $0.1 \mathrm{M} \mathrm{KOH}$. In the investigated range of potentials, basically all catalytic materials do not show redox transitions (i.e., they are not electroactive), and they are characterized by similar capacitive-type currents. Some current increases observed for $\mathrm{FeCN}_{x} / G N P 800_{-} \mathrm{C}$ at potentials lower than $0.3 \mathrm{~V}$ may reflect the presence of larger amounts of iron species (when compared to other compounds studied here). This redox pair was previously attributed to
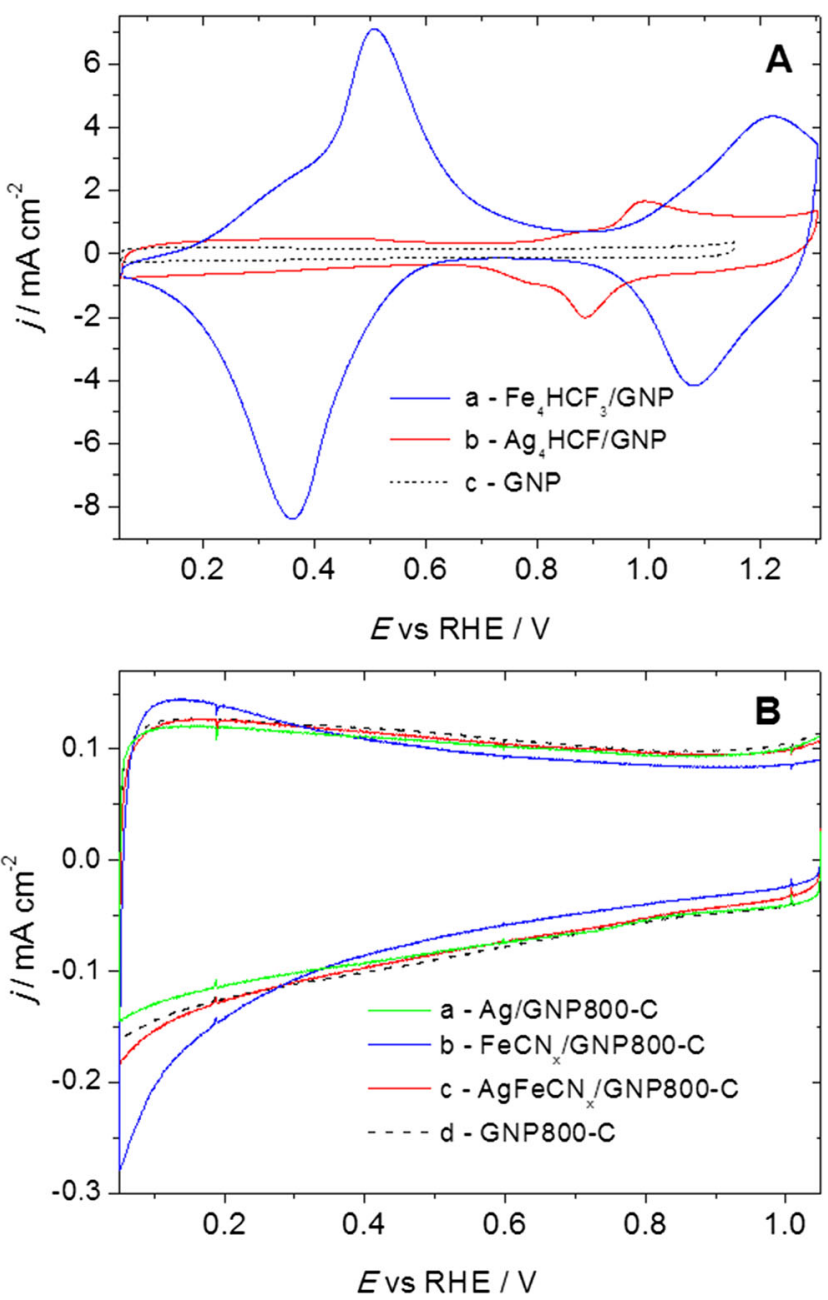

Fig. 4 (A) Cyclic voltammetric responses recorded for electrode films (deposited on glassy carbon disk) of (a) $\mathrm{Fe}_{4} \mathrm{HCF}_{3} / G N P$, (b) $\mathrm{Ag}_{4} \mathrm{HCF} /$ $G N P$, and (c) GNP. Electrolyte: nitrogen-saturated $0.5 \mathrm{~mol} \mathrm{dm}^{-3}$ $\mathrm{K}_{2} \mathrm{SO}_{4}$. Scan rate: $50 \mathrm{mV} \mathrm{s}^{-1}$. (B) Voltammograms recorded for catalytic films of (a) $\mathrm{Ag} / G N P 800-C$, (b) $\mathrm{FeCN}_{x} / G N P 800-\mathrm{C}$, (c) $\mathrm{AgFeCN} \mathrm{N}_{x} /$ GNP800-C, and (d) GNP800-C. Electrolyte: nitrogen-saturated $0.1 \mathrm{~mol} \mathrm{dm}^{-3} \mathrm{KOH}$. Scan rate: $10 \mathrm{mV} \mathrm{s}^{-1}$

transition between $\mathrm{Fe}(\mathrm{OH})_{2}$ and $\mathrm{Fe}(\mathrm{OH})_{3}$ (coming from iron core) [20].

\section{Oxygen Reduction Reaction}

Figure 5a illustrates background-subtracted (normalized) RDE responses recorded in the oxygen-saturated $0.1 \mathrm{M}$ $\mathrm{KOH}$ (at $1600 \mathrm{rpm}$ ) at the disk electrode covered with different catalytic films. The results indicate that all three catalysts, $\mathrm{Ag} / \mathrm{GNP} 800-\mathrm{C}$ (curve a), $\mathrm{FeCN} \mathrm{N}_{x} / G N P 800-\mathrm{C}$ (curve b), and $\mathrm{AgFeCN} / \mathrm{GNP800-C}$ (curve c), are much more active than bare (annealed) GNP800-C carrier (curve d) in terms of higher catalytic currents and lower overpotentials of the oxygen reduction process. What is even more important, the onset and half-wave potentials for oxygen reduction are slightly shifted toward more positive values in the case of $\mathrm{AgFeCN} N_{x}$ 

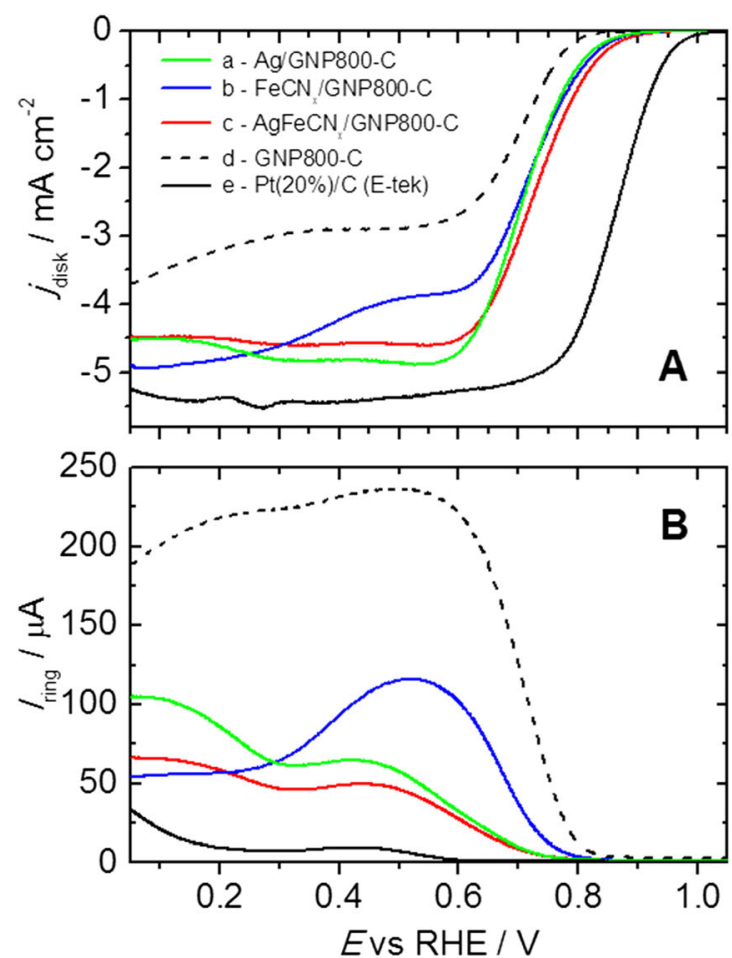

Fig. 5 Normalized (background-subtracted) rotating disk (A) and ring (B) voltammograms recorded during oxygen reduction at the films of (a) $\mathrm{Ag} / G N P 800-\mathrm{C}$, (b) $\mathrm{FeCN} N_{x} / G N P 800-\mathrm{C}$, (c) $\mathrm{AgFeCN_{x }} / G N P 800-\mathrm{C}$, (d) GNP800-C, and (e) Pt/C (E-tek) in the oxygen-saturated $0.1 \mathrm{~mol} \mathrm{dm}^{-3}$

GNP800-C relative to both $\mathrm{Ag} / \mathrm{GNP} 800-\mathrm{C}$ and $\mathrm{FeCN} /$ GNP800-C, thus indicating the enhanced activity of that sample. It is also noteworthy that, while the convective-diffusionlimiting current plateaus are reached (at about $0.6 \mathrm{~V}$ ) in the case of the Ag-containing samples (curves a and c), the response characteristic of $\mathrm{FeCN}_{x} / G N P 800-\mathrm{C}$ (curve b) is somewhat distorted as the initial plateau is followed by further current increases (at potentials lower than $0.5 \mathrm{~V}$ ). Such behavior may reflect changes in the oxygen reduction mechanism including the number of electrons involved in the process. Interpretation of the oxygen reduction RDE curves recorded at lower potentials in alkaline media may be somewhat complicated due to the competition for $\mathrm{O}_{2}$ between metallic centers and different forms of carbon (existing here as GNP, Vulcan additive, and $\mathrm{CN}$ shell) which also exhibit activity toward oxygen reduction [30]. Finally, it should be noted that the half-wave potential for oxygen reduction at the $\mathrm{AgFeCN}_{\mathrm{x}} /$ GNP800-C catalyst $(\sim 0.71 \mathrm{~V})$ is still ca. $120 \mathrm{mV}$ less positive than that characteristic of conventional carbon-supported platinum ( $\sim 0.83 \mathrm{~V})$ (Fig. 5a, curve e). However, comparison to conventional $\mathrm{Pt} / \mathrm{C}$ (containing 3-4 nm Pt nanoparticles) is not straightforward here because our catalysts have not been optimized as yet, e.g., with respect to sizes of nanoparticles. The annealing step during preparation of our samples has involved long-term high-temperature pyrolysis (to generate $\mathrm{CN}$ shells), and, under such conditions, the metallic nanoparticles undergo
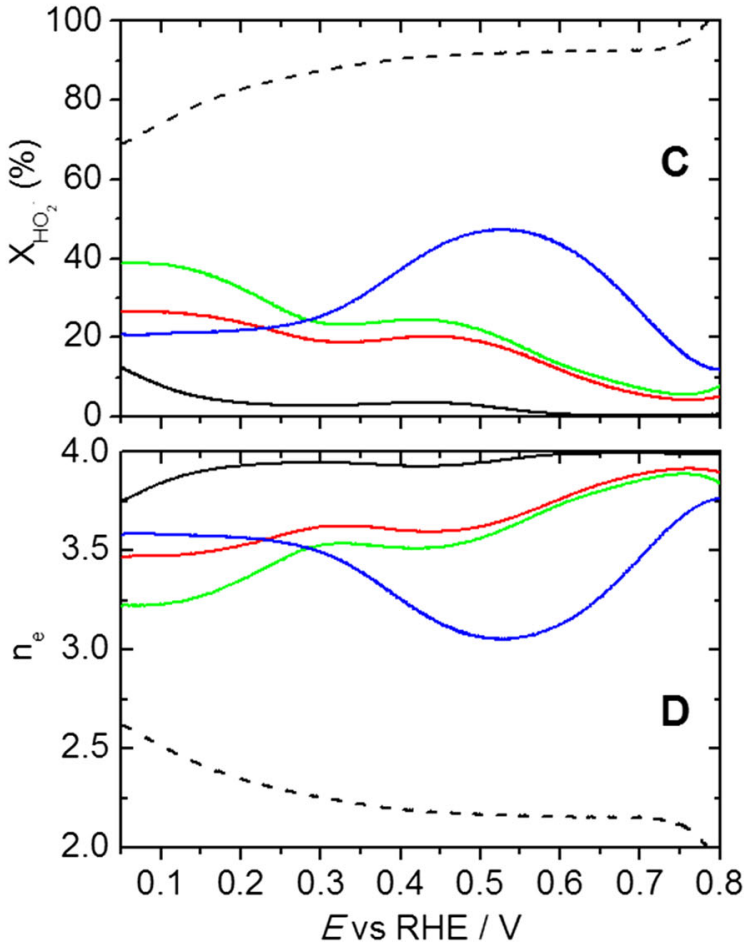

$\mathrm{KOH}$ at the scan rate of $10 \mathrm{mV} \mathrm{s}^{-1}$ and the rotation rate of $1600 \mathrm{rpm}$. (C) Formation of the hydrogen peroxide-type intermediate and (D) monitoring of number of exchanged electrons during oxygen reduction under conditions of RRDE voltammetric experiments

inevitable aggregation. Perhaps, by application of rapid heating and by shortening the period of pyrolysis, fabrication of smaller particles is feasible. Further research is along this line.

The oxygen reduction reaction in alkaline media may proceed by direct four-electron (Eq. (1)) or indirect two-electron (Eqs. (2) and (3)) pathways [59].

$\mathrm{O}_{2}+2 \mathrm{H}_{2} \mathrm{O}+4 \mathrm{e}^{-} \rightarrow 4 \mathrm{OH}^{-}$

$\mathrm{O}_{2}+\mathrm{H}_{2} \mathrm{O}+2 \mathrm{e}^{-} \rightarrow \mathrm{HO}_{2}^{-}+\mathrm{OH}^{-}$

$\mathrm{HO}_{2}^{-}+\mathrm{H}_{2} \mathrm{O}+2 \mathrm{e}^{-} \rightarrow 3 \mathrm{OH}^{-}$

Alternatively, the intermediate form $\left(\mathrm{HO}_{2}^{-}\right)$can undergo disproportionation reaction:

$2 \mathrm{HO}_{2}^{-} \rightarrow 2 \mathrm{OH}^{-}+\mathrm{O}_{2}$

It is apparent from Fig. $5 \mathrm{~b}$ (where the amount of the $\mathrm{HO}_{2}{ }^{-}$ intermediate formed during electroreduction of oxygen has been monitored at the platinum ring electrode) that although Ag/GNP800-C (curve a), $\mathrm{FeCN}_{x} / G N P 800-\mathrm{C}$ (curve b), and

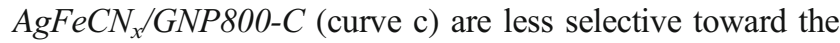
four-electron reduction of oxygen in comparison to the standard $\operatorname{Pt}(20 \%) / \mathrm{C}$ (curve e), they exhibit much lower currents corresponding to oxidation of the $\mathrm{HO}_{2}{ }^{-}$intermediate relative to the unmodified GNP800-C carrier (curve d). In the case of 
Ag-containing samples (curves a and c in Fig. 5b), the $\mathrm{HO}_{2}^{-}$ oxidation currents have considerably decreased at potentials higher than $0.3 \mathrm{~V}$ relative to the silver-free system containing only iron (curve b in Fig. 5b).

Upon consideration of both $\mathrm{HO}_{2}{ }^{-}$oxidation (ring) and $\mathrm{O}_{2}$ reduction disk currents (Fig. 5a,b), the relative (percentage) formation of intermediate product and the corresponding number of transferred electrons $\left(\mathrm{n}_{\mathrm{e}}\right)$ per oxygen molecule involved in the oxygen reduction were calculated using the following equations $[5,60,61]$ :

$$
\begin{aligned}
& \mathrm{X}_{\mathrm{HO}_{2}^{-}}=\frac{200 I_{\mathrm{R}} / \mathrm{N}}{I_{\mathrm{D}}+I_{\mathrm{R}} / \mathrm{N}} \\
& \mathrm{n}_{\mathrm{e}}=\frac{4 I_{\mathrm{D}}}{I_{\mathrm{D}}+I_{\mathrm{R}} / \mathrm{N}}
\end{aligned}
$$

where $I_{\mathrm{R}}$ was the ring current, $I_{\mathrm{D}}$ was the disk current, and $N$ was the collection efficiency of the RRDE assembly. Figure $5 \mathrm{c}$ shows the dependence of $\mathrm{X}_{\mathrm{HO} 2}$-plotted versus the potential applied to the disk electrode. It is apparent from Fig. $5 \mathrm{c}$ that, at potentials higher than $0.3 \mathrm{~V}$ (i.e., in a region characteristic of the cathode operation in a fuel cell), the fraction of produced hydrogen peroxide-type intermediate is lower (below 20\%) for $\mathrm{AgFeCN} / G N P 800-C$ (curve c) relative to both $\mathrm{Ag} / \mathrm{GNP} 800-\mathrm{C}$ (up to $25 \%$, curve a) and $\mathrm{FeCN} / \mathrm{GNP800-C}$ (up to $47 \%$, curve b). Furthermore, as expected, at unmodified GNP800-C carrier (Fig. 5c, curve d), relative amount of hydrogen peroxide-type intermediate is on the level of $90 \%$ whereas, at the standard $\mathrm{Pt}(20 \%) / \mathrm{C}$ (Fig. 5c, curve e), it is only $4 \%$. The dependence of the number of exchanged electrons $\left(\mathrm{n}_{\mathrm{e}}\right)$ plotted versus the disk potential (Fig. 5d) implies that, at potentials close to $0.5-0.6 \mathrm{~V}$, the oxygen reduction at $\mathrm{FeCN}_{x} / G N P 800-\mathrm{C}$ proceeds partially via the two-electron route (the value of $\mathrm{n}_{\mathrm{e}}$ is around 3 ). Obviously higher values of $\mathrm{n}_{\mathrm{e}}$ have been observed for silver-containing systems. Indeed, the $\mathrm{n}_{\mathrm{e}}$ parameter characteristic of $\mathrm{AgFeCN} N_{x} /$ GNP800-C has been the highest, and it approaches most closely the one observed for standard $\mathrm{Pt}(20 \%) / \mathrm{C}$. The results presented in Fig. 5 imply that silver is an effective component of the catalytic materials in terms of increasing their activity and selectivity toward 4-electron reduction of oxygen in alkaline environment. Although not optimized as yet, the combination of $\mathrm{Ag}$ with $\mathrm{Fe}$ within $\mathrm{AgFeCN} / G N P 800-\mathrm{C}$ seems to be particularly advantageous, and it makes it attractive alternative for possible applications in alkaline fuel cells. By comparison to literature concerning the application of nanostructured Agbased catalysts for oxygen reduction in alkaline media, it can be concluded that $\mathrm{AgFeCN} / G N P 800-C$ has comparable performance relative to such materials as $\mathrm{Ag}_{4} \mathrm{Sn} / \mathrm{Vulcan}$ [38], $\mathrm{CoOx}-\mathrm{Ag} / \mathrm{rGO}$ [34], $\mathrm{Ag} / \mathrm{GO} / \mathrm{C}$ [62], $\mathrm{Ag} / \mathrm{rGO}$ [63], and to some Vulcan-supported Ag nanoparticles [9, 64, 65]. On the other hand, the activity has been still lower than that characteristic of $\mathrm{FeAgPc} / \mathrm{KB}(600)$ [37], $\mathrm{AgFe}_{\text {lotus }} /$ Vulcan [40], and
$\mathrm{Ag} / \mathrm{N}-\mathrm{rGO}[66]$ systems. Nevertheless, precise comparison of performances of various catalysts reported in literature is rather difficult, due to differences in morphologies and textures of supports, shapes and sizes of nanoparticles, loadings of catalysts, compositions of electrolytes, and their concentrations.

\section{Importance of Pretreatment in Acid Medium}

Electrochemical characterization and electrocatalytic activity of the catalysts were further diagnosed after treatment in acid medium (the preconditioning step, P). The materials, $\mathrm{Ag} / G N P 800-\mathrm{C}, \mathrm{FeCN} \mathrm{N}_{x} / G N P 800-\mathrm{C}$, and $A g F e C N_{x} / G N P 800-C$, were subjected to continuous potential cycling in the nitrogen-saturated $0.1 \mathrm{M} \mathrm{HClO}_{4}$. The gradual decreases of currents characteristic of silver and iron species have been observed for all samples (for simplicity, data are not shown here), thus implying their dissolution into the bulk of the electrolyte. The abovementioned experiments have been terminated when no further changes in electrochemical responses are observed. Figure 6 presents cyclic voltammetric responses recorded in $0.1 \mathrm{M} \mathrm{KOH}$ solution of GC electrodes covered with resulting residues (after washing them with water). It is evident that signals coming from the formation of silver oxides/hydroxides and their reduction (Fig. 6a,c) as well as the iron redox transitions (Fig. 6b) are much suppressed after preconditioning in perchloric acid (solid lines) when compared to untreated samples (dashed lines) which confirms the significant loss of metallic species in all pretreated catalysts. It is noteworthy that the extent of changes varies from sample to sample, and the current suppressions after preconditioning are particularly apparent for $A g / G N P 800-C$ (Fig. 6a, solid line) and $A g F e C N_{x} / G N P 800-C$ (Fig. 6c, solid line). Addition items of information are apparent upon comparison of Fig. 6a,c. First, the positive shift (ca. $25 \mathrm{mV}$ ) of the $\mathrm{Ag}$ reduction peaks in $\mathrm{AgFeCN} N_{x}$ GNP800-C (relative to $A g / G N P 800-C$ ) implies the existence of the reduced (metallic) silver up to higher potentials in the presence of iron species (here, as before [37], partial charge density transfer from $\mathrm{Fe}$ to $\mathrm{Ag}$ or changes in particle size of $\mathrm{Ag}$ can be postulated). Obviously, the voltammetric characteristics of silver may also reflect the Ag loading and its surface structure $[8,38,62,64,67]$. Simple comparison of charges under the oxidation and reduction peaks of Ag clearly implies that, in the case of $\mathrm{AgFeCN} / G N P 800-\mathrm{C}$ catalyst, the electrochemically active surface area (EASA) of silver is about $50 \%$ of that observed for $A g / G N P 800-C$. The EASA was calculated from the charge corresponding to the reduction of silver oxide (Eq. (7) [8, 62, 64]), which was clearly visible at 1.02 and $1.04 \mathrm{~V}$ in Fig. 6a,c, according to Eq. (8) [64]: 

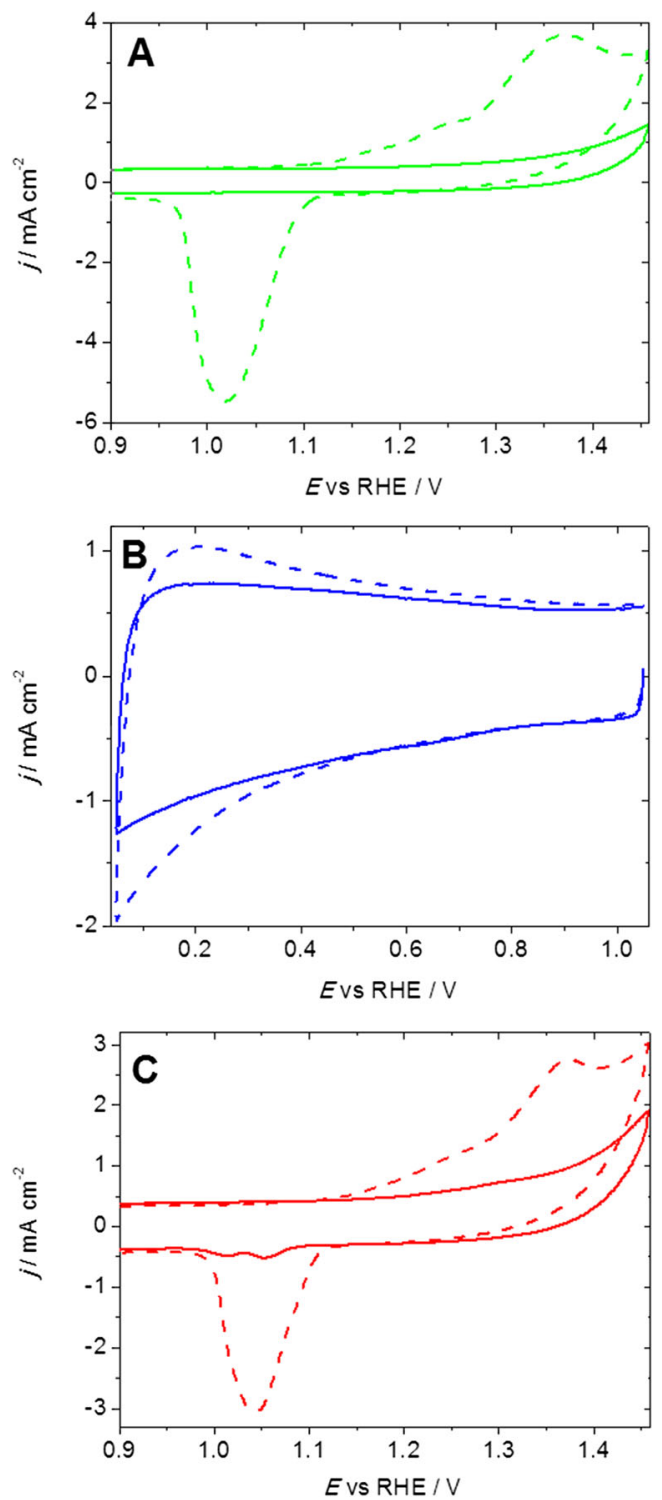

Fig. 6 Cyclic voltammograms recorded for catalytic films of (A) $\mathrm{Ag} /$ GNP800-C, (B) $\mathrm{FeCN}_{x} / G N P 800-\mathrm{C}$, and (C) $\mathrm{AgFeCN} / \mathrm{GNP800-C}$ recorded in $0.1 \mathrm{~mol} \mathrm{dm}^{-3} \mathrm{KOH}$ (at $100 \mathrm{mV} \mathrm{s}^{-1}$ ) before (dashed lines) and after (solid lines) preconditioning $(P)$ in $0.1 \mathrm{~mol} \mathrm{dm}^{-3} \mathrm{HClO}_{4}$

$\mathrm{Ag}_{2} \mathrm{O}+\mathrm{H}_{2} \mathrm{O}+2 \mathrm{e}^{-} \rightarrow 2 \mathrm{Ag}+2 \mathrm{OH}^{-}$

$\mathrm{EASA}=\frac{Q_{\mathrm{O}}}{Q_{\mathrm{O}, \mathrm{ML}} \times \mathrm{L}_{\mathrm{Ag}}}$

where:

$Q_{\mathrm{O}} \quad$ surface oxide reduction charge per unit area $\left(\mathrm{C} \mathrm{m}^{-2}\right)$

$Q_{\mathrm{O}, \mathrm{ML}}$ charge due to the reduction of a monolayer of surface oxide per unit area $\left(4.2 \mathrm{C} \mathrm{m}^{-2}\right.$ adopted from $\mathrm{Pt}$ surface oxide reduction $[8,64])$

$\mathrm{L}_{\mathrm{Ag}} \quad$ loading of $\mathrm{Ag}$ per unit area $\left(\mathrm{g} \mathrm{m}^{-2}\right)$

The estimated EASA of $\mathrm{Ag}$ in $\mathrm{Ag} / G N P 800-C$ (loading of $\mathrm{Ag}$ is about $60 \mu \mathrm{g} \mathrm{cm} \mathrm{cm}^{-2}$ ) and $A g F e C N_{x} / G N P 800-$
$C$ (loading of $\mathrm{Ag}$ is about $53 \mu \mathrm{g} \mathrm{cm}{ }^{-2}$ ) are as follows: 17.7 and $8.2 \mathrm{~m}^{2} \mathrm{~g}^{-1}$, respectively. A number of factors should be taken into account here: somewhat (about $11 \%$ ) lower amounts of Ag (according to the synthesis procedure described in the "Experimental" section), higher average crystallite size (as it comes from the XRD analysis), as well as partial over-coating of catalytic centers by $\mathrm{CN}$ shells (as apparent from Fig. 1h) are applicable to the $A g F e C N_{x} / G N P 800-C$ samples.

Electrochemical experiments aiming at evaluation of catalytic activity and selectivity in the oxygen reduction at the acid-pretreated $A g / G N P 800-C-P, F e C N_{x} / G N P 800$ $C-P$, and $A g F e C N_{x} / G N P 800-C-P$ catalysts were conducted under identical conditions as for untreated samples. The results are presented in Fig. 7. First, the system's performance for $\mathrm{O}_{2}$ reduction is only slightly lowered at $\mathrm{FeCN}_{x} / G N P 800-\mathrm{C}-\mathrm{P}$ relative to untreated $\mathrm{FeCN} /$ GNP800-C (Fig. 7b, solid and dotted lines, respectively). Furthermore, the current decreases are only slightly more pronounced for $\mathrm{AgFeCN} / G N P 800-C-P$ relative to $\mathrm{FeCN} \mathrm{N}_{x} / G N P 800-\mathrm{C}$ (Fig. 7c, solid and dotted lines, respectively). However, the greatest change (drop) in activity has been observed for $A g / G N P 800-C-P$ in comparison to its untreated form (Fig. 7a, solid and dotted lines, respectively). In the latter case, the performance and selectivity toward $\mathrm{O}_{2}$ reduction closely approach that characteristic for bare GNP800-C (compare curves $\mathrm{d}$ in Fig. 5a,b). The obtained results can be rationalized as follows: contrary to bare GNP-supported silver nanoparticles (prepared by simple impregnation method), the application of such inorganic coordination compounds as Prussian Blue and its silver analog as precursors tends to preserve the systems' active sites even after preconditioning in an acid electrolyte. The increased stability should be ascribed to the existence of catalytic centers (iron and silver) in the form of coordination complexes strongly bonded to the surface of carbon nitride shell, as suggested previously [23-27].

\section{Consideration of Graphene Oxide as Support}

For comparative purposes, we have also performed additional diagnostic experiments utilizing the sample of $\mathrm{AgFeCN} \mathrm{N}_{x}$ deposited onto Graphene Oxide (GO), prepared in an analogous manner as described previously for $\mathrm{AgFeCN} / \mathrm{GNP} 800$. It can be expected that GO, while containing numerous oxygen functionalities and surface defects, could be a proper candidate for obtaining well-dispersed catalysts (in spite of using high pyrolysis temperature during synthesis). In addition, cyanides, which are released upon decomposition of hexacyanoferrates, are known to act as reducing agents (their presence should lead to partial reduction of GO to the more conducting reduced graphene oxide, rGO). Because basic 
Fig. 7 Normalized (backgroundsubtracted) rotating disk and ring voltammetric responses recorded during oxygen reduction at the films of $\left(\mathbf{A}, \mathbf{A}^{\prime}\right) A g / G N P 800-C$, $\left(\mathbf{B}, \mathbf{B}^{\prime}\right) \mathrm{FeCN} / \mathrm{GNP} 800-\mathrm{C}$, and $\left(\mathbf{C}, \mathbf{C}^{\prime}\right) \mathrm{AgFeCN} / G N P 800-\mathrm{C}$ in the oxygen-saturated $0.1 \mathrm{~mol} \mathrm{dm}^{-3} \mathrm{KOH}$ at the scan rate of $10 \mathrm{mV} \mathrm{s}^{-1}$ and the rotation rate of $1600 \mathrm{rpm}$ before (dashed lines) and after preconditioning in $0.1 \mathrm{~mol} \mathrm{dm}^{-3} \mathrm{HClO}_{4}$ (abbreviated as $P$, solid lines)
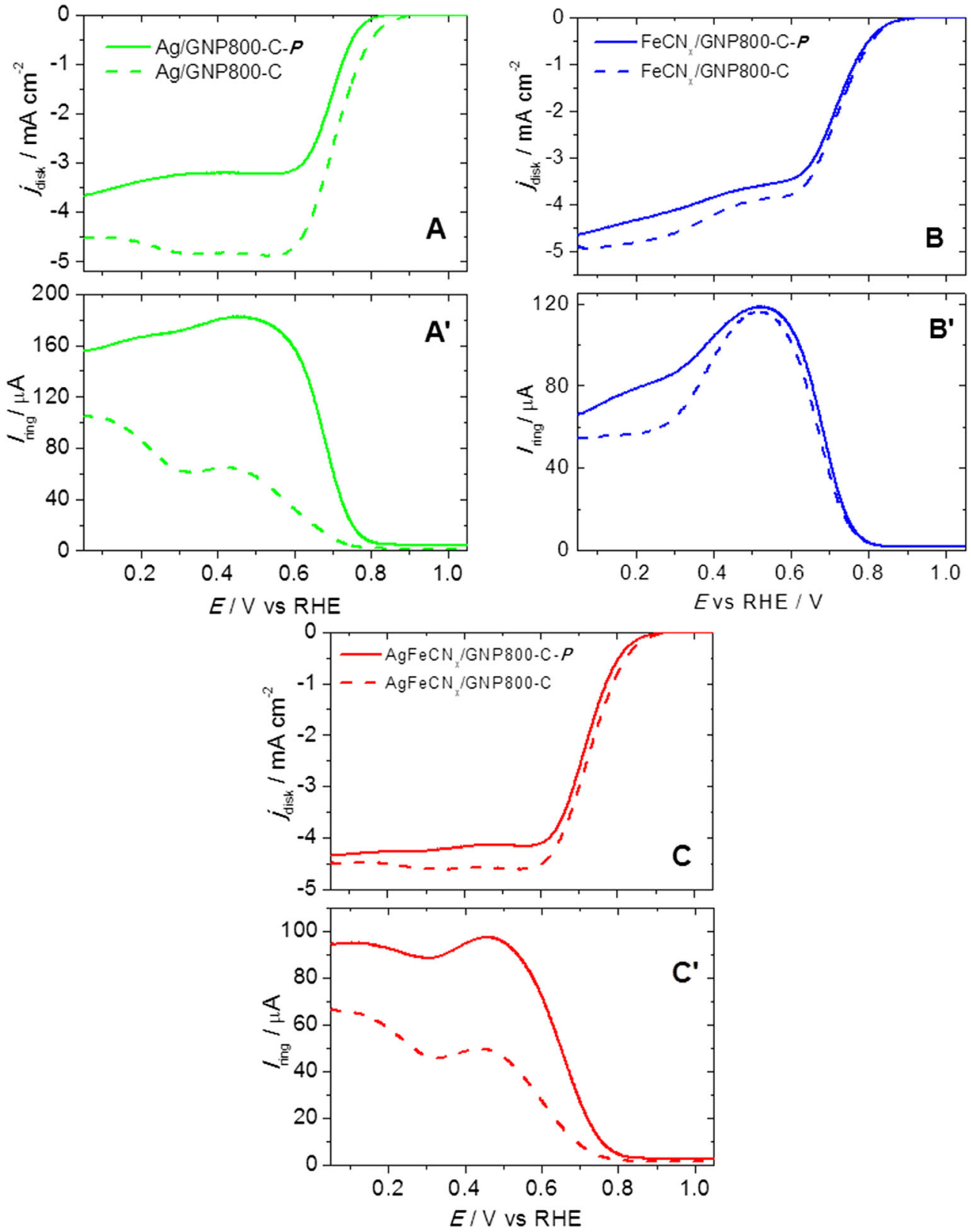

physicochemical properties of GO samples considered here were described elsewhere [68], we limit our microscopic characterization to the basic TEM image of $\mathrm{AgFeCN}_{x} / G O 800$ and present the electrocatalytic performance toward $\mathrm{O}_{2}$ reduction only in comparison to $\mathrm{AgFeCN} / \mathrm{GNP800}$. As evident from Fig. 8a, the catalytic material $\mathrm{AgFeCN} / G O 800$ is characterized by fairly uniform distribution of crystals (with diameters on the level of $50 \mathrm{~nm}$ with only some larger up to ca. $100 \mathrm{~nm}$ ) on the support. However, it is apparent from the comparison of RRDE data (Fig. 8b,c) that the activity and selectivity of the GO-based $\mathrm{AgFeCN} / \mathrm{GO} 00-\mathrm{C}$, despite of the presence of Vulcan as "separator" between graphene sheets, is much lower

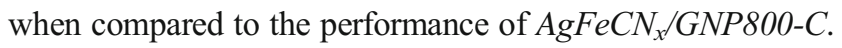

Most probably, the $\mathrm{O}_{2}$ and water management are still largely hindered and/or the electron conductivity is not sufficiently high in the $\mathrm{AgFeCN} / \mathrm{GO} 000-\mathrm{C}$ case. The present results favor the use of the graphene derivatives (rather than graphene oxide) as supports in the oxygen reduction electrocatalysis.

\section{Conclusions}

It has been demonstrated for the first time that thermal decomposition under the inert atmosphere of silver(I) hexacyanoferrate(II), deposited on graphene nanoplatelets, produces nanomaterial containing silver and iron species 

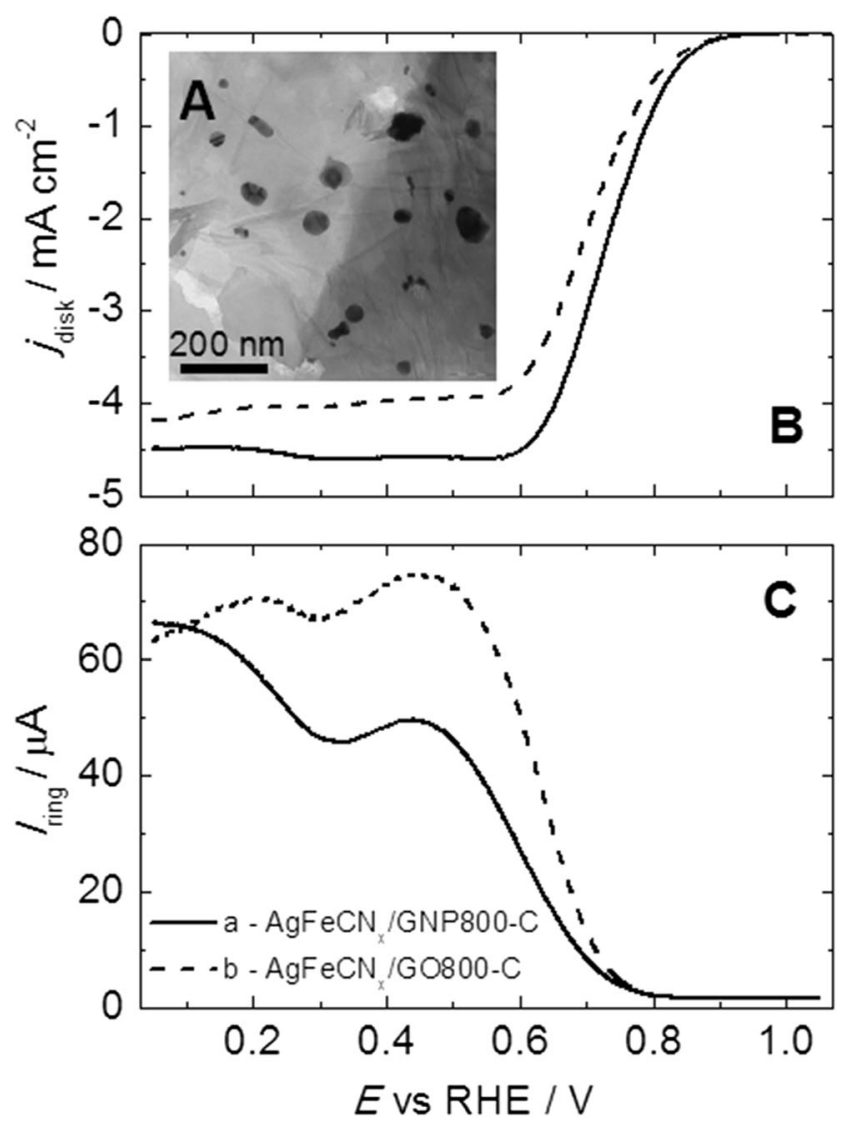

Fig. 8 (A) TEM image of $\mathrm{AgFeCN} / G O 800$. Normalized rotating disk (B) and ring $(\mathbf{C})$ voltammograms recorded during oxygen reduction at the films of (a) $\mathrm{AgFeCN} N_{x} / G N P 800-C$ and (b) $\mathrm{AgFeCN} N_{x} / G O 800-C$ in the oxygen-saturated $0.1 \mathrm{~mol} \mathrm{dm}^{-3} \mathrm{KOH}$ at the scan rate of $10 \mathrm{mV} \mathrm{s}^{-1}$ and the rotation rate of $1600 \mathrm{rpm}$

coordinated to carbon nitride shells and exhibiting the remarkable efficiency toward oxygen reduction process in alkaline environment. It is important to note that, at the graphenenanoplatelet-supported mixed silver-iron carbon nitrides, the reaction proceeds at more positive potential values in comparison to both bare silver nanoparticles and the iron-carbon nitride systems themselves (prepared separately under the same conditions on graphene-nanoplatelet carriers). Furthermore, amounts of the hydrogen peroxide-type intermediate (generated during reduction of oxygen in the potential range where cathode is expected to operate in a real fuel cell) are lower at the composite material mentioned previously. In this respect, high activity of silver toward decomposition of the undesirable intermediate $\left(\mathrm{HO}_{2}{ }^{-}\right)$seems to be of primary importance. Another important factor is that the systems based on carbon nitrides retain their electrocatalytic activity even after continuous polarization in acidic medium thus implying strong fixation of metal complexes to $\mathrm{CN}$ shells.

Acknowledgments We acknowledge the European Commission through the Graphene Flagship - Core 1 project [Grant number GA-696656] and the Maestro Project [2012/04/A/ST4/00287 (National Science Center, Poland)]
Open Access This article is distributed under the terms of the Creative Commons Attribution 4.0 International License (http:// creativecommons.org/licenses/by/4.0/), which permits unrestricted use, distribution, and reproduction in any medium, provided you give appropriate credit to the original author(s) and the source, provide a link to the Creative Commons license, and indicate if changes were made.

\section{References}

1. G. Merle, M. Wessling, K. Nijmeijer, Anion exchange membranes for alkaline fuel cells: a review. J. Membr. Sci. 377(1-2), 1-35 (2011)

2. M.A. Hickner, A.M. Herring, E.B. Coughlin, Anion exchange membranes: current status and moving forward. J. Polym. Sci. B Polym. Phys. 51(24), 1727-1735 (2013)

3. N. Ramaswamy, S. Mukerjee, Influence of inner- and outer-sphere electron transfer mechanisms during electrocatalysis of oxygen reduction in alkaline media. J. Phys. Chem. C 115(36), 18015-18026 (2011)

4. J.S. Spendelow, A. Wieckowski, Electrocatalysis of oxygen reduction and small alcohol oxidation in alkaline media. Phys. Chem. Chem. Phys. 9(2654), 2654-2675 (2007)

5. M. Chatenet, L. Genies-Bultel, M. Aurousseau, R. Durand, F. Andolfatto, Oxygen reduction on silver catalysts in solutions containing various concentrations of sodium hydroxide - comparison with platinum. J. Appl. Electrochem. 32(10), 1131-1140 (2002)

6. L. Tammeveski, H. Erikson, A. Sarapuu, J. Kozlova, P. Ritslaid, V. Sammelselg, K. Tammeveski, Electrocatalytic oxygen reduction on silver nanoparticle/multi-walled carbon nanotube modified glassy carbon electrodes in alkaline solution. Electrochem. Commun. 20, 15-18 (2012)

7. F.W. Campbell, S.R. Belding, R. Baron, L. Xiao, R.G. Compton, Hydrogen peroxide electroreduction at a silver-nanoparticle array: investigating nanoparticle size and coverage effects. J. Phys. Chem. C 113(21), 9053-9062 (2009)

8. A. Fazil, R. Chetty, Synthesis and evaluation of carbon nanotubes supported silver catalyst for alkaline fuel cell. Electroanalysis 26(11), 2380-2387 (2014)

9. J. Guo, A. Hsu, D. Chu, R. Chen, Improving oxygen reduction reaction activities on carbon-supported Ag nanoparticles in alkaline solutions. J. Phys. Chem. C 114(10), 4324-4330 (2010)

10. J. Masa, A. Zhao, W. Xia, M. Muhler, W. Schuhmann, Metal-free catalysts for oxygen reduction in alkaline electrolytes: influence of the presence of $\mathrm{Co}, \mathrm{Fe}, \mathrm{Mn}$ and $\mathrm{Ni}$ inclusions. Electrochim. Acta 128, 271-278 (2014)

11. K.-K. Türk, I. Kruusenberg, J. Mondal, P. Rauwel, J. Kozlova, L. Matisen, V. Sammelselg, K. Tammeveski, Oxygen electroreduction on $\mathrm{MN}_{4}$-macrocycle modified graphene/multi-walled carbon nanotube composites. J. Electroanal. Chem. 756, 69-76 (2015)

12. H.T. Chung, J.H. Won, P. Zelenay, Active and stable carbon nanotube/nanoparticle composite electrocatalyst for oxygen reduction. Nat. Commun. 4, 1922 (2013)

13. R. Jäger, P.E. Kasatkin, E. Härk, P. Teppor, T. Romann, R. Härmas, I. Tallo, U. Mäeorg, U. Joost, P. Paiste, K. Kirsimäe, E. Lust, The effect of $\mathrm{N}$ precursors in Fe-N/C type catalysts based on activated silicon carbide derived carbon for oxygen reduction activity at various pH values. J. Electroanal. Chem. 823, 593-600 (2018)

14. V. Neburchilov, H. Wang, J.J. Martin, W. Qu, A review on air cathodes for zinc-air fuel cells. J. Power Sources 195(5), 1271$1291(2010)$

15. F. Bidault, D.J.L. Brett, P.H. Middleton, N.P. Brandon, Review of gas diffusion cathodes for alkaline fuel cells. J. Power Sources 187(1), 39-48 (2009) 
16. D. Geng, N. Ding, T.S.A. Hor, Z. Liu, X. Sun, Y. Zong, Potential of metal-free "graphene alloy" as electrocatalysts for oxygen reduction reaction. J. Mater. Chem. A 3(5), 1795-1810 (2015)

17. M. del Cueto, P. Ocón, J.M.L. Poyato, Comparative study of oxygen reduction reaction mechanism on nitrogen-, phosphorus-, and boron-doped graphene surfaces for fuel cell applications. J. Phys. Chem. C 119(4), 2004-2009 (2015)

18. J. Liu, P. Song, Z. Ning, W. Xu, Recent advances in heteroatomdoped metal-free electrocatalysts for highly efficient oxygen reduction reaction. Electrocatalysis 6(2), 132-147 (2015)

19. Z. Lin, G. Waller, Y. Liu, M. Liu, C.-P. Wong, Facile synthesis of nitrogen-doped graphene via pyrolysis of graphene oxide and urea, and its electrocatalytic activity toward the oxygen-reduction reaction. Adv. Energy Mater. 2(7), 884-888 (2012)

20. R. Zhou, S.Z. Qia, Fe/N co-doped graphitic carbon bulb for high performance oxygen reduction reaction. Chem. Commun. 51(35), 7516-7519 (2015)

21. K. Sawai, N. Suzuki, Heat-treated transition metal hexacyanometallates as electrocatalysts for oxygen reduction insensitive to methanol. J. Electrochem. Soc. 151(5), A682 (2004)

22. K. Sawai, Y.-S. Maeda, Peroxide elimination activity of heat-treated transition metal hexacyanoferrate catalysts for oxygen reduction in alkaline solution. J. Electrochem. Soc. 155(1), B27 (2008)

23. V. Di Noto, E. Negro, S. Polizzi, K. Vezzu, L. Toniolo, G. Cavinato, Synthesis, studies and fuel cell performance of "core-shell" electrocatalysts for oxygen reduction reaction based on a PtNix carbon nitride "shell" and a pyrolyzed polyketone nanoball "core". Int. J. Hydrog. Energy 39(6), 2812-2827 (2014)

24. E. Negro, S. Polizzi, K. Vezzu, L. Toniolo, G. Cavinato, V. Di Noto, Interplay between morphology and electrochemical performance of "core-shell" electrocatalysts for oxygen reduction reaction based on a PtNix carbon nitride "shell" and a pyrolyzed polyketone nanoball "core". Int. J. Hydrog. Energy 39(6), 2828-2841 (2014)

25. V. Di Noto, E. Negro, K. Vezzù, F. Bertasi, G. Nawn, Developments, and perspectives of carbon nitride-based electrocatalysts for application in low-temperature FCs. Electrochem. Soc. Interface 24, 59 (2015)

26. K. Vezzù, A. Bach Delpeuch, E. Negro, S. Polizzi, G. Nawn, F. Bertasi, G. Pagot, K. Artyushkova, P. Atanassov, V. Di Noto, Fecarbon nitride "core-shell" electrocatalysts for the oxygen reduction reaction. Electrochim. Acta 222, 1778-1791 (2016)

27. E. Negro, A. Bach Delpeuch, K. Vezzu, G. Nawn, F. Bertasi, A. Ansaldo, V. Pellegrini, B. Dembinska, S. Zoladek, K. Miecznikowski, I. Rutkowska, M. Skunik-Nuckowska, P.J. Kulesza, F. Bonaccorso, V. Di Noto, Towards Pt-free anion-exchange membrane fuel cells: Fe-Sn carbon nitride-graphene coreshell electrocatalysts for the oxygen reduction reaction. Chem. Mater. 30(8), 2651-2659 (2018)

28. Y. Liu, H. Wang, D. Lin, J. Zhao, C. Liu, J. Xie, Y. Cui, A Prussian blue route to nitrogen-doped graphene aerogels as efficient electrocatalysts for oxygen reduction with enhanced active site accessibility. Nano Res. 10(4), 1213-1222 (2017)

29. R. Liu, X. Yu, G. Zhang, S. Zhang, H. Cao, A. Dolbecq, P. Mialane, B. Keitad, L. Zhi, Polyoxometalate-mediated green synthesis of a 2D silver nanonet/graphene nanohybrid as a synergistic catalyst for the oxygen reduction reaction. J. Mater. Chem. A 1(38), 11961 (2013)

30. Y. Yang, Y. Zhou, Particle size effects for oxygen reduction on dispersed silver + carbon electrodes in alkaline solution. J. Electroanal. Chem. 397(1-2), 271-278 (1995)

31. B.B. Blizanac, P.N. Ross, N.M. Markovic, Oxygen reduction on silver low-index single-crystal surfaces in alkaline solution: rotating ring DiskAg (hkl) studies. J. Phys. Chem. B 110(10), 4735-4741 (2006)

32. Y. Sun, M. Yang, J. Pan, P. Wang, W. Li, P. Wan, Manganese dioxide-supported silver bismuthate as an efficient electrocatalyst for oxygen reduction reaction in zinc-oxygen batteries. Electrochim. Acta 197, 68-76 (2016)

33. Q. Wu, L. Jiang, L. Qi, L. Yuan, E. Wang, G. Sun, Electrocatalytic activity and stability of $\mathrm{Ag}-\mathrm{MnOx} / \mathrm{C}$ composites toward oxygen reduction reaction in alkaline solution. Electrochim. Acta $\mathbf{1 2 3}$ 167-175 (2014)

34. F. Sun, G. Zhang, Y. Xu, Z. Chang, P. Wan, Y. Li, X. Sun, Promoted oxygen reduction activity of $\mathrm{Ag} /$ reduced graphene oxide by incorporated CoOx. Electrochim. Acta 132, 136-141 (2014)

35. Y. Wang, Y. Liu, X. Lu, Z. Li, H. Zhang, X. Cui, Y. Zhang, F. Shi, Y. Deng, Silver-molybdate electrocatalysts for oxygen reduction reaction in alkaline media. Electrochem. Commun. 20, 171-174 (2012)

36. Q. Yi, H. Chu, M. Tang, Z. Yang, Q. Chen, X. Liu, Carbon nanotube-supported binary silver-based nanocatalysts for oxygen reduction reaction in alkaline media. J. Electroanal. Chem. $\mathbf{7 3 9}$, 178-186 (2015)

37. H.A. Miller, M. Bevilacqua, J. Filippi, A. Lavacchi, A. Marchionni, M. Marelli, S. Moneti, W. Oberhauser, E. Vesselli, M. Innocenti, F. Vizza, Nanostructured Fe-Ag electrocatalysts for the oxygen reduction reaction in alkaline media. J. Mater. Chem. A 1(42), 13337 (2013)

38. Y. Lu, N. Zhang, L. An, X. Li, D. Xia, Synthesis of high dispersed intermetallic $\mathrm{Ag}_{4} \mathrm{Sn} / \mathrm{C}$ and its enhanced oxygen reduction reaction activity. J. Power Sources 240, 606-611 (2013)

39. F.H.B. Lima, J.F.R. de Castro, E.A. Ticianelli, Silver-cobalt bimetallic particles for oxygen reduction in alkaline media. J. Power Sources 161(2), 806-812 (2006)

40. G.A. El-Nagar, I. Lauermann, R.M. Sarhan, C. Roth, Hierarchically structured iron-doped silver (Ag-Fe) lotus flowers for efficient oxygen reduction reaction. Nanoscale 10(15), 7304-7310 (2018)

41. E. Quesnel, F. Roux, F. Emieux, P. Faucherand, E. Kymakis, G. Volonakis, F. Giustino, B. Martín-García, I. Moreels, S.A. Gürsel, A.B. Yurtcan, V. Di Noto, A. Talyzin, I. Baburin, D. Tranca, G. Seifert, L. Crema, G. Speranza, V. Tozzini, P. Bondavalli, G. Pognon, C. Botas, D. Carriazo, G. Singh, T. Rojo, G. Kim, W. $\mathrm{Yu}$, C.P. Grey, V. Pellegrini, Graphene-based technologies for energy applications, challenges and perspectives. 2D Mater 2, 030204 (2015)

42. D. Higgins, P. Zamani, A. Yu, Z. Chen, The application of graphene and its composites in oxygen reduction electrocatalysis: a perspective and review of recent progress. Energy Environ. Sci. 9(2), 357390 (2016)

43. J. Zak, E. Negro, I.A. Rutkowska, B. Dembinska, V. Di Noto, P.J. Kulesza, in Encyclopedia of Interfacial Chemistry: Surface Science and Electrochemistry. Graphene-Based Nanostructures in Electrocatalytic Oxygen Reduction (Elsevier, Amsterdam, 2018), pp. 651-659 ISBN: 978-0-12-809894-3

44. P.J. Kulesza, J.K. Zak, I.A. Rutkowska, B. Dembinska, S. Zoladek, K. Miecznikowski, E. Negro, V. Di Noto, P. Zelenay, Elucidation of role of graphene in catalytic designs for electroreduction of oxygen. Current Opinion in Electrochemistry 9, 257-264 (2018)

45. Y. Li, Y. Li, E. Zhu, T. McLouth, C.-Y. Chiu, X. Huang, Y. Huang, Stabilization of high-performance oxygen reduction reaction $\mathrm{Pt}$ electrocatalyst supported on reduced graphene oxide/carbon black composite. J. Am. Chem. Soc. 134(30), 12326-12329 (2012)

46. Y. Shao, S. Zhang, C. Wang, Z. Nie, J. Liu, Y. Wang, Y. Lin, Highly durable graphene nanoplatelets supported Pt nanocatalysts for oxygen reduction. J. Power Sources 195(15), 4600-4605 (2010)

47. Y. Cui, S.I. Kundalwal, S. Kumar, Gas barrier performance of graphene/polymer nanocomposites. Carbon 98, 313-333 (2016)

48. D. He, K. Cheng, T. Peng, M. Pan, S. Mu, Graphene/carbon nanospheres sandwich supported PEM fuel cell metal nanocatalysts with remarkably high activity and stability. J. Mater. Chem. A 1(6), 2126-2132 (2013) 
49. J. Jung, H.J. Park, J. Kim, S.H. Hur, Highly durable Pt/graphene oxide and $\mathrm{Pt} / \mathrm{C}$ hybrid catalyst for polymer electrolyte membrane fuel cell. J. Power Sources 248, 1156-1162 (2014)

50. J.-S. Lee, K. Jo, T. Lee, T. Yun, J. Cho, B.-S. Kim, Facile synthesis of hybrid graphene and carbon nanotubes as a metal-free electrocatalyst with active dual interfaces for efficient oxygen reduction reaction. J. Mater. Chem. A 1(34), 9603 (2013)

51. D. Ji, Y. Wang, S. Chen, Y. Zhang, L. Li, W. Ding, Z. Wei, Nitrogen-doped graphene wrapped around silver nanowires for enhanced catalysis in oxygen reduction reaction. J. Solid State Electrochem. 22(7), 2287-2296 (2018)

52. A. Qaseem, F. Chen, X. Wu, N. Zhang, Z. Xia, Ag, Co/graphene interactions and its effect on electrocatalytic oxygen reduction in alkaline media. J. Power Sources 370, 1-13 (2017)

53. J.M. Linge, H. Erikson, A. Sarapuu, M. Merisalu, M. Rähn, L. Matisen, V. Sammelselg, K. Tammeveski, Electroreduction of oxygen on nitrogen-doped graphene oxide supported silver nanoparticles. J. Electroanal. Chem. 794, 197 (2017)

54. S. Hu, T. Han, C. Lin, W. Xiang, Y. Zhao, P. Gao, F. Du, X. Li, Y. Sun, Enhanced electrocatalysis via 3D graphene aerogel engineered with a silver nanowire network for ultrahigh-rate zinc-air batteries. Adv. Funct. Mater. 27, 1700041 (2017)

55. P.J. Kulesza, K. Doblhofer, The membrane properties of Prussian Blue films on electrodes. J. Electroanal. Chem. 274(1-2), 95-105 (1989)

56. P.J. Kulesza, S. Zamponi, M. Malik, K. Miecznikowski, M. Berrettoni, R. Marassi, Spectroelectrochemical identity of Prussian blue films in various electrolytes: comparison of timederivative voltabsorptometric responses with conventional cyclicvoltammetry. J. Solid State Electrochem. 1(1), 88-93 (1997)

57. P.J. Kulesza, T. Jedral, Z. Galus, A new development in polynuclear inorganic films: silver(I)/“crosslinked" nickel(II)hexacyanoferrate(III, II) microstructures. Electrochim. Acta 34(6), 851-853 (1989)

58. U. Schroder, F. Scholz, The solid-state electrochemistry of metal octacyanomolybdates, octacyanotungstates, and hexacyanoferrates explained on the basis of dissolution and reprecipitation reactions. Inorg. Chem. 39(5), 1006-1015 (2000)

59. E. Yeager, Dioxygen electrocatalysis: mechanisms in relation to catalyst structure. J. Mol. Catal. 38(1-2), 5-25 (1986)

60. O. Antoine, R. Durand, RRDE study of oxygen reduction on Pt nanoparticles inside Nafion ${ }^{\circledR}: \mathrm{H} 2 \mathrm{O} 2$ production in PEMFC cathode conditions. J. Appl. Electrochem. 30(7), 839-844 (2000)

61. T.J. Schmidt, U.A. Paulus, H.A. Gasteiger, R.J. Behm, The oxygen reduction reaction on a $\mathrm{Pt} /$ carbon fuel cell catalyst in the presence of chloride anions. J. Electroanal. Chem. 508(1-2), 41-47 (2001)

62. L. Yuan, L. Jiang, J. Liu, Z. Xia, S.Wana, G. Sun, Facile synthesis of silver nanoparticles supported on three-dimensional graphene oxide/carbon black composite and its application for oxygen reduction reaction. Electrochim. Acta 135, 168-174 (2014)

63. E.J. Lim, S.M. Choi, M.H. Seo, Y. Kim, S. Lee,W.B. Kim, Highly dispersed $\mathrm{Ag}$ nanoparticles on nanosheets of reduced graphene oxide for oxygen reduction reaction in alkaline media. Electrochem. Commun. 28, 100-103 (2013)

64. S. Maheswari, P. Sridhar, S. Pitchumani, Carbon-supported silver as cathode electrocatalyst for alkaline polymer electrolyte membrane fuel cells. Electrocatalysis 3(1), 13-21 (2012)

65. T. Van Cleve, E. Gibara, S. Linic, Electrochemical oxygen reduc tion reaction on Ag nanoparticles of different shapes. ChemCatChem 8(1), 256-261 (2016)

66. R. Zhou, S.Z. Qiao, Silver/nitrogen-doped graphene interaction and its effect on electrocatalytic oxygen reduction. Chem. Mater. 26(20), 5868-5873 (2014)

67. M. Hepel, M. Tomkiewicz, Study of the initial stages of anodic oxidation of polycrystalline silver in $\mathrm{KOH}$ solutions. J. Electrochem. Soc. 131(6), 1288 (1984)

68. S. Zoladek, I.A. Rutkowska, M. Blicharska, K. Miecznikowski, W. Ozimek, J. Orlowska, E. Negro, V. Di Noto, P.J. Kulesza, Evaluation of reduced-graphene-oxide-supported gold nanoparticles as catalytic system for electroreduction of oxygen in alkaline electrolyte. Electrochim. Acta 233, 113-122 (2017) 